\title{
Escrituras (de) qom en el dominio religioso (Chaco argentino, 1950-1970)
}

\section{Escritas (de) qom no domínio religioso (Chaco argentino, 1950-1970)}

\author{
Victoria Soledad Almiron ${ }^{1}$ \\ Ana Padawer ${ }^{2}$
}

DOI: http://dx.doi.org/10.20435/tellus.vi43.703

Resumen: Este artículo analiza la producción de materiales escritos en lengua qom o bilingües qom-castellano, realizados por indígenas de dicho colectivo en un contexto religioso de inserción misional protestante, en el noreste de Argentina entre 1960-1970. Los textos responden a finalidades diversas: religiosas, productivas y educativas; correspondiendo por lo tanto a géneros tales como epístolas, reflexiones bíblicas y cartillas de alfabetización para la enseñanza de la lectura y la escritura en qom. El análisis que realizamos propone indicios sobre algunas modalidades de apropiación indígena del proceso de escrituración en lengua qom en el marco de la historia de la cultura escrita, para la cual utilizamos fuentes escritas, visuales y orales.

Palabras clave: pueblos indígenas; cultura escrita; dominio religioso; apropiación.

Resumo: Este artigo analisa a produção de materiais escritos em língua qom ou bilíngues qom-castelhano, realizados por indígenas deste coletivo num contexto religioso de inserção protestante, no nordeste da Argentina, entre 1960-1970. Os textos respondem a finalidades diversas: religiosas, produtivas e educativas; correspondem, portanto, a gêneros como epístolas, reflexões bíblicas e cartilhas de alfabetização para o ensino da leitura e da escrita em qom. A análise que realizamos propõe indícios de algumas modalidades de apropriação indígena do processo de escrituração em língua qom no âmbito da história da cultura escrita, para a qual utilizamos fontes escritas, visuais e orais.

Palavras-chave: povos indígenas; cultura escrita; domínio religioso; apropriação.

${ }^{1}$ Instituto de Investigaciones Geohistóricas (CONICET-UNNE), Resistencia, Chaco, Argentina.

${ }^{2}$ CONICET- UBA, Lanús, Buenos Aires, Argentina. 


\section{INTRODUCCIÓN}

A mediados del año 2019 se realizó en la provincia del Chaco (Argentina) la Feria del Libro Chaqueño. En el evento el referente indígena Orlando Sánchez presentó su libro, "Vocabulario Qom", ante un público numeroso compuesto por referentes, estudiantes y docentes indígenas, funcionarios estatales, integrantes de la Sociedad Bíblica Argentina e investigadoras/es del medio. En una lectura ampliada que desdibujó fronteras temporales entre el pasado y el presente, Sánchez describía que la escritura del vocabulario fue el resultado de más de setenta años de trabajo junto a misioneros protestantes, cuya génesis fue el proceso de escrituración de la lengua qom y la traducción de la Biblia a este idioma, aunque actualmente el libro adquiere nuevos sentidos políticos, lingüísticos y educativos:

[Es] Un nuevo aporte para la descolonización de nuestra historia [qom] y también de la educación bilingüe e intercultural [...]. Fue pensado para el estudio de la gramática y también para la alfabetización en el idioma dentro de las instituciones educativas; [...] para que esto sirva como material de investigación, de aprendizaje de nuestras generaciones que hoy están haciendo un esfuerzo para adecuarse a otra situación de vida, otro nivel de aprendizaje [...], creyendo que la educación también es una fortaleza que puede cambiar una estructura de un pueblo como nuestro pueblo. (Discurso de presentación de Sánchez, 2019. Las aclaraciones en cursiva son nuestras)

Tomando como reflexión inicial el evento y buscando profundizar en la historia de la cultura escrita entre pueblos indígenas del Chaco argentino, en este artículo queremos hacer un recorrido por el periodo genealógico de estandarización de la lengua qom y la configuración de modalidades de apropiación de la escritura en qom entre indígenas de esta etnia, procesos a los que remite Sánchez en su discurso. Como "entrada a lo escrito" (CHARTIER, 2002), analizamos materiales en qom o bilingües qom-castellano producidos en el dominio religioso, circunscribiendo a las décadas de 1960-1970.

Desde una mirada en la larga duración, y entendiendo a la historia como herramienta para construir modelos de inteligibilidad crítica de procesos actuales (CHARTIER, 1999), a través del análisis proponemos que la "descolonización de la historia qom y de la educación bilingüe e intercultural" que menciona Sánchez en ocasión de presentar el Vocabulario Qom, constituye también una herramienta de descolonización de la lengua qom. Este proceso implica una reapropiación de los 
procesos de escritura, realizada en el contexto de inserción protestante entre indígena del Chaco argentino varias décadas atrás, los que son actualizados en un nuevo contexto de relación entre el colectivo indígena, el Estado y las congregaciones religiosas.

Para el análisis recurrimos a los aportes provenientes del campo de la historia de la cultura escrita, en particular al término apropiación como un concepto que permite acentuar el rol activo de los sujetos involucrados en tomar para sí y hacer uso de los recursos culturales objetivados en su ambiente inmediato, entre ellos la cultura escrita (ROCKWELL, 2000; 2006; 2008). En distanciamiento con el paradigma de la reproducción, donde la apropiación es unidireccional y se refiere a la concentración de capital simbólico por parte de los grupos sociales dominantes, la apropiación puede partir de otros sectores sociales permitiendo apreciar el valor diferencial que un objeto o recurso cultural puede tener para diferentes grupos en una sociedad, y examinar los cambios que se producen en dichos recursos cuando son apropiados (ROCKWELL, 2006).

De esta manera problematizamos el supuesto teórico que sostiene que los sujetos "ingresan" o "acceden" a lo escrito, enfatizando que los seres humanos producen cotidianamente bienes materiales y también simbólicos en relación con el mundo letrado; producción que a lo largo del tiempo va configurando el lugar de la cultura escrita en los distintos grupos sociales. En tanto la configuración es dinámica, el lugar de la cultura escrita es cambiante y se transforma permanentemente (OLIVEIRA GALVÃO, 2010, p. 219).

La producción de recursos (por ejemplo, materiales escritos) y prácticas culturales (v. la escritura), dependen de la identidad histórica de cada comunidad; por ello resulta necesario otorgar un contenido sociohistórico a la apropiación (CHARTIER, 1999). Asimismo, atender a las relaciones sociales donde "hay siempre una voluntad de monopolio, de control, de propiedad, y que la apropiación no se da por sí misma sino como resultado de un conflicto, de una lucha, de una voluntad confrontada con otra" (CHARTIER, 1999, p. 162). La exploración de dichos contenidos en la apropiación de la cultura escrita permite analizar las situaciones asimétricas y relaciones de dominación en las que está inscripta dialécticamente en tanto producto y proceso de transformación.

La noción de dominios de apropiación permite aludir a los espacios o situaciones sociales tipificadas y reguladas por normas donde los sujetos se ponen en 
contacto y apropian de la cultura escrita (ROCKWELL, 2000; 2006). Como adelantamos, en el artículo referimos exclusivamente al dominio de apropiación religioso, que resultó clave como articulador del resto de los dominios en el contexto considerado.

Chaco es una provincia ubicada en el nordeste de Argentina donde residen miembros indígenas qom, moqoit y wichí. Es una zona de lenguas en contacto, las dos primeras etnias pertenecen a la familia lingüística Guaycurú, la tercera a la Mataco-mataguaya. El término Qom es un etnónimo que "hace traslucir una identidad colectiva y étnica englobadora [...], funciona como una categoría que se opone a la de 'no-indígena' o 'blanco', los 'rocshe', aglutina una diversidad de parcialidades (grupos sociopolíticos) y variedades lingüísticas" (TOLA, 2010, p. 169). Los qom también han sido denominados tobas, exónimo peyorativo que significa "frentones" y se utiliza aún en la actualidad (TOLA, 2010).

Este trabajo se encuentra organizado en tres subtítulos. En el primero hacemos una descripción general de la inserción misional protestante en el Chaco argentino. En el segundo nos referimos al lugar y las finalidades que tuvo la difusión de la cultura escrita en los proyectos misionales, donde analizamos materiales monolingües en qom o bilingües qom-castellano escritos por indígenas. En el tercero presentamos a modo de recapitulación una concisa conclusión de estos procesos históricos y reflexionamos sobre algunos vínculos entre el pasado y el presente.

Para los resultados expuestos recurrimos al análisis de fuentes escritas, visuales y orales, obtenidas en consultas a archivos nacionales e internacionales así como durante un trabajo de campo realizado en el marco de una Tesis doctoral ${ }^{3}$. El corpus incluye materiales publicados e inéditos del periodo comprendido entre 1950-1970: entre las fuentes escritas se incluyen textos impresos y manuscritos; mientras que las fuentes visuales fueron exclusivamente fotográficas. El fondo documental obtenido está conformado por materiales utilizados para la enseñanza de lectura y escritura (cartillas de alfabetización), epístolas religiosas de indígenas o no-indígenas, documentos oficiales eclesiásticos como informes, boletines de difusión, planes, proyectos, etcétera. Las traducciones que se presentan en el texto fueron

3 Título: "Historia de apropiación de la cultura escrita entre el pueblo qom del noroeste chaqueño (1960-1976)". Financiada por del Consejo Nacional de Investigaciones Científicas y Técnicas (CONICET) a través de una beca interna doctoral (Resolución n. 4358/12 y n. 1738/14). Periodo: 2013- 2018. Lugar de trabajo: Instituto de Investigaciones en Educación, Universidad Nacional del Nordeste. Directora: Dra. Ana Padawer, Co-directora: Dra. Teresa Laura Artieda. 
realizadas por el docente y referente qom David García, a quien expresamos nuestro agradecimiento por sus continuos aportes a las investigaciones desarrolladas.

\section{LA CONFIGURACIÓN DEL DOMINIO RELIGIOSO: MISIONEROS PROTESTANTES ENTRE INDÍGENAS DEL CHACO ARGENTINO}

En este apartado presentamos una descripción de la expansión misional protestante entre los indígenas del Chaco argentino, que condujo a la conformación de la primera iglesia nativa: la Iglesia Evangélica Unida (IEU), así como a la emergencia del evangelismo étnico. Estos procesos, que ya han sido descriptos por otros investigadores del campo de la antropología, serán considerados como constitutivos del dominio religioso de apropiación de la cultura escrita: a través de ellos analizaremos el papel de los espacios religiosos en la construcción del indígena hermano lector de la palabra divina, de una comunidad indígena lectora, y luego de indígenas hermanos que escriben en su idioma.

Si bien focalizamos en el dominio religioso, en el Chaco argentino la construcción del "indígena hermano" se dio a la par de narrativas civilizatorias e integracionistas que hacían eco, aunque con reinterpretaciones leídas desde las políticas misionales, de los discursos estatales relativos a la "cuestión indígena". En este sentido consideramos el carácter polisémico del término "religión" para referirnos a los usos y apropiaciones diferenciales de grupos y sujetos sociales, en condiciones históricas y entramados de poder particulares, de procesos ligados a las creencias (CERIANI CERNADAS, 2013a, p. 11).

Hacia finales del siglo XIX, durante el proceso de conformación del Estado moderno argentino, la preexistencia de los indígenas en los llamados Territorios Nacionales constituyó una problemática política para la elite dirigente de la época: su resolución se ligaba a la expansión territorial y capitalista, pero también a una "cuestión social" que convocó a distintos sectores de la sociedad como agentes colonizadores para integrar a los indígenas a la Nación (TRINCHERO, 2000; TORRES FERNÁNDEZ, 2007/2008; MASES, 2010; GÓMEZ, 2011).

En ese contexto de despojo territorial, de agresión militar y explotación, se inició la fundación de misiones protestantes entre indígenas de las actuales provincias argentinas de Chaco, Formosa y Salta (CERIANI CERNADAS, 2009; 2013b; TRINCHERO, 2000). En Chaco la iglesia anglicana fue pionera en la fundación de 
emplazamientos misionales entre wichí, qom y pilagá entre los años 1914-1933 (GORDILLO, 2005; CERIANI CERNADAS, 2013b). La política misional anglicana proveyó una nueva "solución" al problema de integración indígena, conformando una agenda de intervenciones en educación, salud, evangelización, y trabajo industrial que "devino en procesos imbricados de incorporación y alterización de las poblaciones nativas, resultantes de la puesta en marcha de comunalizaciones respecto de tres sentidos de pertenencia yuxtapuestos: el nacional, el religioso y el étnico" (TORRES FERNÁNDEZ, 2007/2008, p. 143).

Sumada a la intervención anglicana, otras corrientes protestantes concurrieron posteriormente a la evangelización de grupos indígenas de Chaco: misioneros noruegos y suecos pentecostales (en 1920); misioneros ingleses que fundaron la iglesia Emmanuel (1932), norteamericanos pentecostales de las iglesias Go Ye y Gracia y Gloria (principios del ‘40), y en 1943 menonitas estadounidenses (CERIANI CERNADAS, 2011; 2013b).

En estas tres décadas de amplia expansión territorial estatal y capitalista colonizadora, así como de una significativa intervención religiosa entre diversos grupos étnicos del Chaco argentino (pilagá, qom, wichí, moqoit), se asentaron las bases para la construcción de nuevas formas de relaciones interétnicas, tramas diferenciales de poder y prácticas religiosas rituales que conllevaron un paulatino cambio sociorreligioso y la emergencia del "evangelismo étnico" (WRIGHT, 2002; CERIANI CERNADAS, 2007; 2011; 2013b).

Se trató de una coyuntura histórica de migraciones y relocalizaciones espaciales forzadas, que fue acompañada de un movimiento sincrético de apropiación y adaptación selectiva del ideario y de la praxis pentecostal. Ambos procesos dieron forma a nuevas relecturas de la identidad étnica y evangélica qom, y a relaciones con agencias políticas en pos de la obtención de títulos territoriales, mejoras en las condiciones de vida y gestión de la educación (CERIANI CERNADAS, 2018, p. 356).

Entre todas estas influencias, la misión inglesa Emmanuel tuvo especial relevancia como preludio del evangelismo étnico por sus expresiones litúrgicas que se articularon fluidamente con las formas de religiosidad indígena (CERIANI CERNADAS, 2007). Se trataba de una rama pentecostal que funcionó entre la década de 1930 y principios de 1950 en Formosa y Chaco, la política misional procuró alcanzar una asimilación de los indígenas a las formas de vida occidental 
y cristiana, infundir una identidad nacional y un sentimiento patriota. Cristianizar, civilizar e integrar por medio del evangelio, el castellano, la escritura, la agricultura y el trabajo manual (CERIANI CERNADAS, 2009), en palabras de Wright (2002, p. 68) "una misión que quería enseñarles las bondades del Evangelio y transformarlos en útiles y 'civilizados' trabajadores".

Con el emplazamiento de la iglesia Emmanuel comenzó un proceso de apropiación de elementos pentecostales (la teología del Espíritu Santo, el énfasis en los poderes divinos, la curación, las experiencias extáticas y emocionales), los cuales fueron articulados con los complejos cosmológicos y rituales de las sociedades nativas (CERIANI CERNADAS; CITRO, 2005). Además del trabajo con la misión pentecostal inglesa, algunos indígenas comenzaron a difundir entre su pueblo el culto evangélico experimentado con otros misioneros, destacándose la prédica del pilagá Luciano Corona y de los qom Pedro Martínez y Aurelio López quienes después de estar en contacto en Resistencia con el misionero pentecostal Juan Lagar de la misión Go Ye, propagaron el evangelio entre qom del Chaco y Formosa (MAST, 1972; TAMAGNO, 2007 ).

En la confluencia de estas experiencias previas, entre 1930-1940 se crearon iglesias indígenas en la región y surgió el evangelismo étnico o el evangelio (CERIANI CERNADAS, 2011), el cual fue cristalizado e institucionalizado con la creación de la primera iglesia indígena, la Iglesia Evangélica Unida o IEU (WRIGHT, 2002; CERIANI CERNADAS; CITRO, 2005). Desde sus orígenes el evangelio constituyó un espacio dinámico de relaciones de poder, surcado de ambigüedades y rivalidades: un complejo campo sociorreligioso de disputas por "el capital material y simbólico entre las diversas asociaciones (iglesias, ONG, emprendimientos misioneros), donde se articulan relaciones con los otros campos sociales (políticos, educativos, económicos) y se constituyen habitus identitarios específicos" (CERIANI CERNADAS, 2011, p. 6).

La IEU surgió entre los qom de Pampa Aguará4, en el contexto del emprendimiento misional "Nam Cum" iniciado por la iglesia menonita a principios de 1940 (imágenes 1 y 2), articulado con líderes qom quienes se propusieron constituir una institución religiosa autónoma independiente de las iglesias doqshi ${ }^{5}$ (CERIANI CERNADAS, 2018).

4 Paraje rural ubicado en el centro de la provincia del Chaco.

5 Marca de plural que denota al "blanco" y/o "criollo" (CERIANI CERNADAS, 2018). 
Imagen 1 y 2 - Encuentro religioso indígena. Pampa Aguará, mayo de 1955

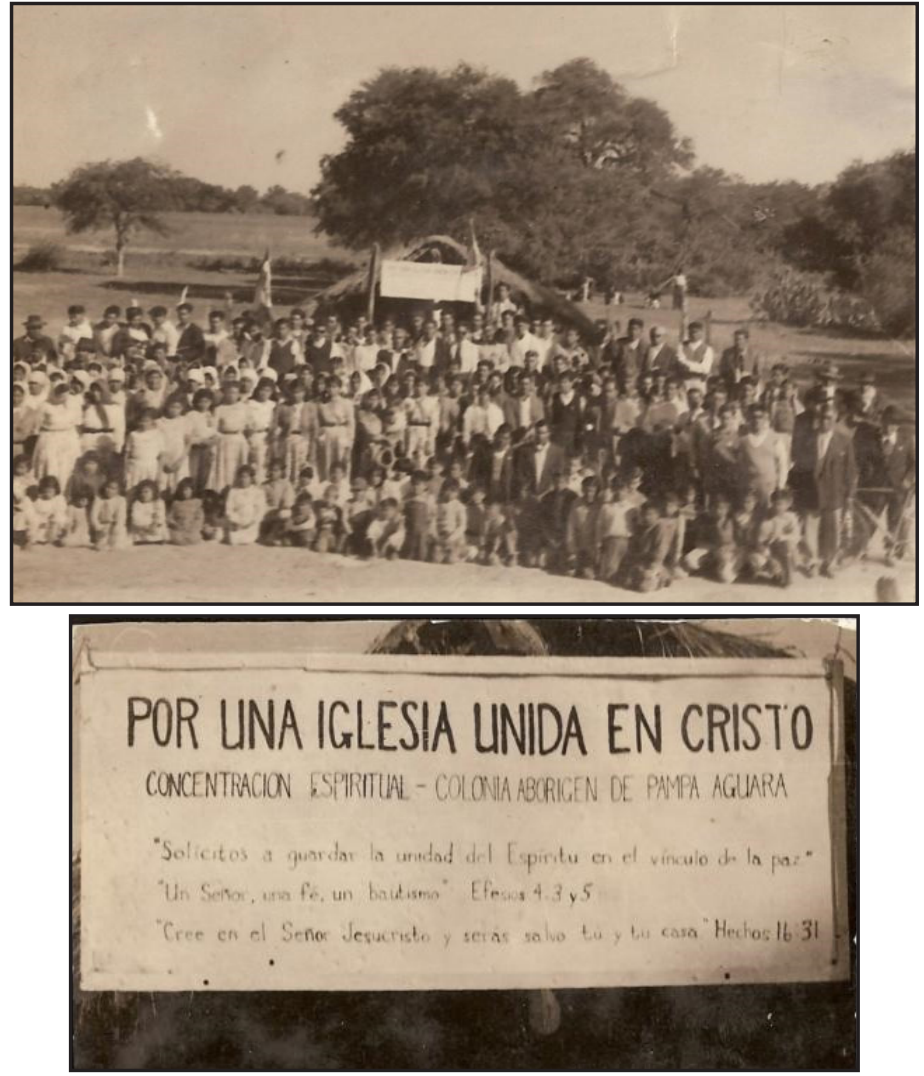

Fuente: Archivo personal David García (2017).

A partir de 1951, Nam Cum estuvo a cargo del matrimonio compuesto por Albert Buckwalter y Lois Litwiller, quienes luego del primer tiempo de trabajo comenzaron a replantear el modelo misional vigente:

Por consiguiente, nuestros primeros años en esta tarea estuvieron llenos de frustraciones continuas; 1 . No entendíamos a los indígenas. 2. Veíamos la imposibilidad de transformar en menonitas a los indígenas de las tres iglesias locales de la misión. 3. El trabajo relacionado con la administración de la misión (educación, agricultura, almacén, etc.) monopolizaba nuestro tiempo y energías y nos dejaba agotados y disgustados, sin ánimos para nuestro ministerio espiritual que en realidad considerábamos la parte primordial. (BUCKWALTER; LITWILLER, 2011, p. 194). 
Ante dichos condicionamientos y el conocimiento del movimiento religioso pentecostal preexistente entre los indígenas, ${ }^{6}$ en 1954 recurrieron al antropólogo y lingüista religioso William Reyburn para realizar un estudio sobre los qom y el movimiento religioso (REYNBURN, [1954] 2003). En el estudio este religioso concluyó:

Encuentro pues cuatro aspectos, además de la evangelización, en las que creo que se necesita que los misioneros colaboren con las iglesias tobas:

A. Capacitación de líderes tobas.

B. Formación cristiana en la iglesia.

C. Traducción de la Biblia.

D; Animar a la búsqueda del cristianismo responsable. (REYBURN, [1954]2003, p. 54).

El estudio incidió en la transformación de la política misional menonita. A finales de los cincuenta disolvieron la misión y asistieron al proceso autonómico entre los qom con la conformación de su propia iglesia, la IEU, registrada oficialmente en 1961 por el Fichero de Culto N. 819 (WRIGHT, 1987). Durante las primeras décadas de consolidación, la institución estuvo a cargo de Aurelio López, quien contaba con una amplia experiencia y reconocimiento como líder religioso entre los indígenas del Chaco y Formosa.

Entre 1958-1968, la IEU fue ampliando su cobertura territorial y étnica: en sus comienzos tenía 800 miembros y 17 congregaciones entre qom y pilagá; hacia 1968 contaba con 2.000 miembros qom, pilagá y moqoit (BUCKWALTER; LITWILLER, 2011, p. 191). Con el mapa siguiente (imagen 3) se tendrá una referencia espacial de la expansión del evangelio en las provincias del Chaco y Formosa y, como daremos cuenta subsiguientemente, la difusión simultánea de la cultura escrita:

\footnotetext{
${ }^{6}$ Al decir de Buckwalter y Litwiller (2011): "Ya existía un movimiento cristiano incipiente que incluía más de veinticinco iglesias en aisladas comunidades en el Chaco central, organizadas por los mismos indígenas" (BUCKWALTER; LITWILLER, 2011, p. 195).
} 
Imagen 3 - Locación de las iglesias, 1971

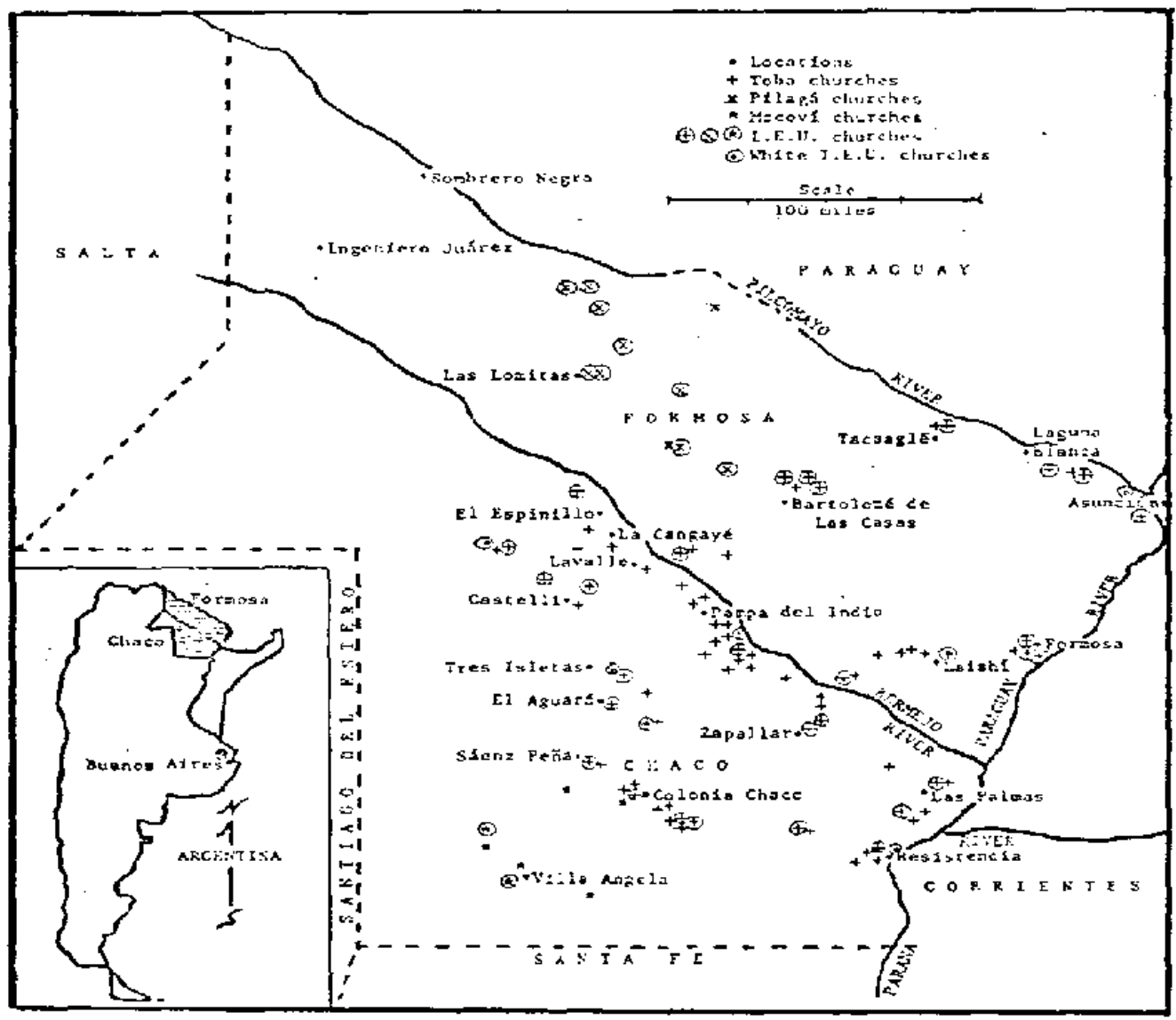

Fuente: Mast, 1972.

Para Buckwalter esto significó una conversión en su tarea misional, en el sentido de autoadscribirse como hermano y no "señor" de los indígenas:

Brothers, not lords

What we missionaries did then, amounted to a conversion experience for us. Instead of condemning the log seat as a sign of "primitiveness", we deliberately accepted God's call to go and sit on it. The log seat with a Toba preacher sitting beside a Mennonite missionary might be considered the symbol of our new relationship. Together we are looking to God; together we are studying his Word; together we are praying to him; together we are following his Spirit; together we are seeking the lost; and together we are 
suffering for the sake of Jesus Crist.' (BUCKWALTER, 1957, p. 9-10. Destacado en original)

En la trayectoria histórica misional protestante entre indígenas del Chaco argentino, esto significó una redefinición en la construcción de los sentidos de la aboriginalidad: el Otro hermano indígena implicó que los qom ocuparan lugares de liderazgo, configurándose nuevas redes de poder político étnico a lo largo de la región. Al interior de la experiencia misional menonita, a partir de esta reconfiguración surge el equipo de "Obreros Fraternales", aún presentes en la actualidad con una fuerte influencia en la formación de los líderes religiosos de la IEU (CERIANI CERNADAS; CITRO, 2005). ${ }^{8}$ Esta reconfiguración, que se traduce en una política misional protestante de formación religiosa basada en la hermenéutica bíblica, permite problematizar el papel de la cultura escrita para así dimensionar los alcances de la autonomía indígena en la constitución del campo sociorreligioso del Evangelio.

Con el giro en la política misional, el eje medular del accionar de los menonitas se reorientó hacia la evangelización en lengua nativa, y a enseñar a los indígenas a leer en su propio idioma: "the Indians shall form a church of the redeemed, and that this body will stand after the missionaries are gone. In order for this to be possible, the Indians must have the Word of God [...] in their mother tongue" (BUCKWALTER, 1951, p. 4). ${ }^{9}$ Para ello, Buckwalter inició la escrituración y estan-

7 En castellano: Hermanos, no señores. Lo que los misioneros hicimos entonces equivalió a una experiencia de conversión para nosotros. En lugar de condenar el asiento de madera como signo de algo "primitivo", deliberadamente aceptamos el llamado de Dios para ir y sentarnos en ese asiento. El asiento de madera con un predicador Toba sentado al lado de un misionero Menonita podría ser considerado el símbolo de nuestra nueva relación. Juntos estamos buscando a Dios, juntos estamos estudiando su Palabra, juntos le estamos rezando, juntos estamos siguiendo su Espíritu, juntos estamos buscando al perdido, y juntos estamos sufriendo por Jesucristo. Traducción realizada por Jesús Lenain del Departamento de Lenguas Extranjeras, Fac. de Humanidades, UNNE.

8 Al decir de César Ceriani Cernadas y Silvia Citro (2005): "Las tareas de apoyo que realizan actualmente los "obreros fraternales" menonitas en la Iglesia Evangélica Unida abarca diferentes actividades, como las visitas de parejas de misioneros a las iglesias (generalmente para los Aniversarios de las mismas o algún Cumpleaños), la asistencia y apoyo a las Convenciones Generales, la realización de "Círculos Bíblicos" y "Estudios Bíblicos" para los pastores y fieles y la edición de un boletín titulado "Nuestro Mensajero" (Qad'aqtaxanaxanec) y otros materiales escritos que son enviados a las iglesias".

9 En castellano: esperamos que los Indios creen una iglesia de redimidos y que este cuerpo sobreviva luego de que los misioneros se retiren. Para que esto sea posible, los Indios deben tener la Palabra 
darización de la lengua qom, y la traducción de la Biblia a este idioma. Respecto del trabajo, en una entrevista la menonita Lois Litwiller señaló lo siguiente:

[...] nuestro trabajo se concentró exclusivamente en relación a la Iglesia entre los Tobas, específicamente en la traducción de la Biblia al Toba, comenzando con el Nuevo Testamento. [...] el incentivo para aprender a leer en Toba entre los/las creyentes Tobas, es leer la Biblia en su idioma, es poder escuchar a Dios hablándoles en su propia lengua. A medida que el traductor toba, asesorado por Alberto, traducía al Toba los libros de la Biblia, Alberto los publicaba en ediciones provisorias que leía durante los servicios religiosos en las iglesias. (LITWILLER, 2016).

Las actividades vinculadas con la cultura escrita devinieron centrales en las acciones misionales. Sumada a la estandarización del qom, Buckwalter escrituró progresivamente el pilagá y el moqoit, elaboró un vocabulario del qom, editó y publicó el periódico "Qad’aqtaxanaxanec" (desde 1954), alfabetizó a indígenas, y enseñó el idioma a otros misioneros protestantes que trabajaban con grupos qom.

En estos procesos de escrituración participaron el líder religioso qom Francisco Rodríguez, y sus hermanos Cristóbal y Roberto Rodríguez (SÁNCHEZ, 2005). El estudio realizado por Wright (1987) aporta elementos para analizar la significación que tuvo por parte de los indígenas la escrituración del idioma: "La cristalización de la lengua a través de textos escritos es un fenómeno que tiene un fuerte impacto entre los toba, ya que les crea por un lado un sentimiento de extrañeza al poder pronunciar voces de la lengua materna leyendo letras del alfabeto castellano" (WRIGHT, 1987, p. 8).

En la tarea de traducción de la Biblia a los idiomas nativos participaron el qom Orlando Sánchez, el moqoit Roberto Ruiz y el pilagá Ramón Tapicero (imagen 4). Para realizar esta tarea, Sánchez, Ruiz y Tapicero fueron capacitados en organizaciones religiosas internacionales: "En el año 1972... yo estaba asistiendo a un curso de escritura y traducción organizado por las Sociedad Bíblica Unida Mundial, junto con el Pastor menonita Alberto Buckwalter, Roberto Ruiz (mocoví) y Ramón Tapicero (Pilagá) en Asunción del Paraguay..." (SÁNCHEZ, 2009, p. 206).

de Dios [...] en su lengua materna. Traducción realizada por Jesús Lenain del Departamento de Lenguas Extranjeras, Fac. de Humanidades, UNNE. 
Imagen 4 - Encuentro de traductores bíblicos, Cerrito Paraguay, 1972. En el medio de la foto Ramón Tapicero, Cornelio Castro y Roberto Ruíz; el primero a la izquierda es Albert Buckwalter.

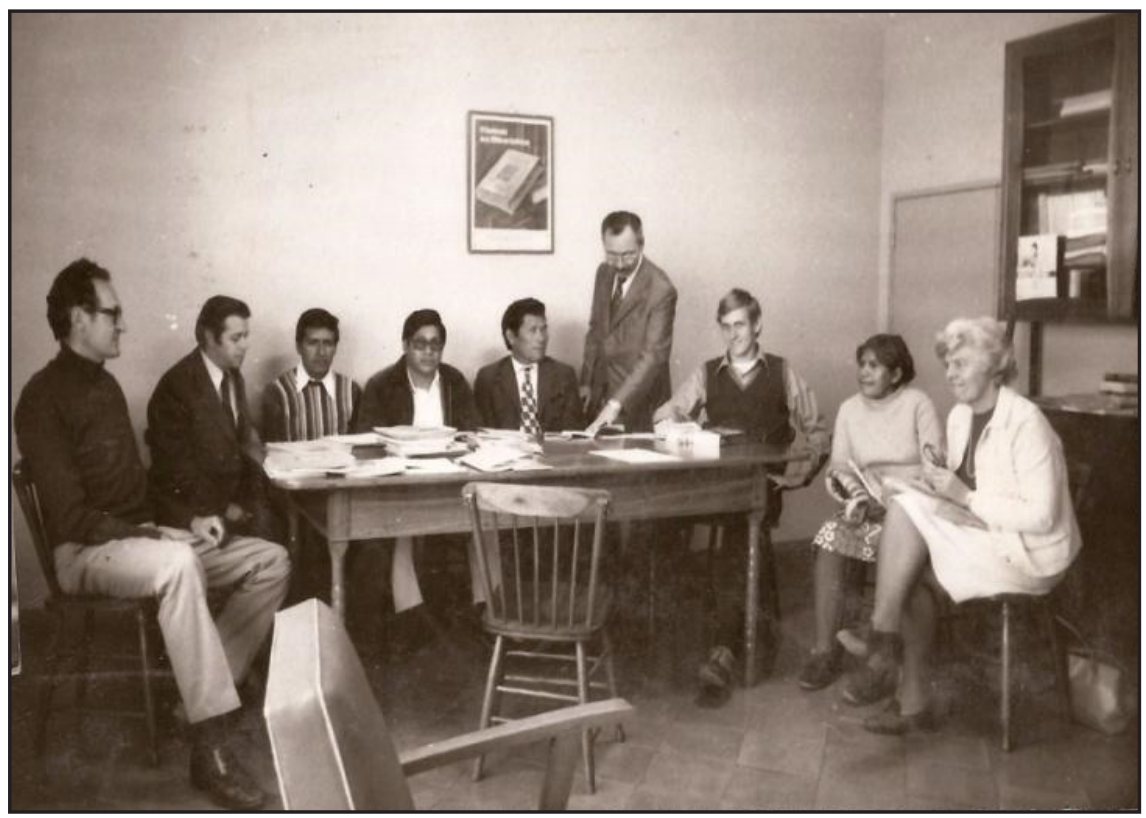

Fuente: Archivo personal David García.

El trabajo lingüístico contó con el auspicio de varias instituciones protestantes ocupadas en la traducción, impresión y divulgación de la Biblia: la citada Sociedad Bíblica Unida (SBU), la Sociedad Bíblica Americana y la Sociedad Bíblica Argentina (SBA). Dentro de los repositorios consultados, también hemos encontrado referencias a intercambios epistolares de Buckwalter con el Instituto Lingüístico de Verano, lo cual sugiere una colaboración con dicha organización para realizar la tarea.

Para el año 1968 esta tarea de traducción se concretó mediante una versión bilingüe qom-castellano del libro de San Marcos. Hacia 1972 el equipo de traductores menonitas e indígenas tradujo Hechos de los Apóstoles, Corintios I y II, Tesalonicenses I y II, Timoteo, Tito, Juan, algunos pasajes bíblicos y más de 120 historias del Antiguo Testamento (MAST, 1972). Dentro de la política misional menonita, la selección de dichos libros no fue arbitraria: 
Se recomienda que estos libros sean traducidos al idioma toba, dándoles así, la base o el centro de la verdad del Nuevo Testamento. Marcos es claramente el mejor libro inicial para esta gente indígena que tan recientemente se ha convertido del paganismo. Hechos es importantísimo para darles la historia de la Iglesia. Juan da una vista diferente y significativa de Jesús. Romano brinda una síntesis excelente de las doctrinas básicas del Nuevo Testamento. Para ciertos problemas especiales, como por ejemplo la tendencia de los tobas a ser dependientes de otros, la Segunda Epístola a los Tesalonicenses sería muy útil. (BUCKWALTER; LITWILLER, 2011, p. 224-5. El destacado en negrita es nuestro)

Desde una perspectiva sociolingüística, encontramos similitudes con el proceso de "reducción literaria indigenista" acontecido en la década del '70 entre los guaraní del Paraguay por la intervención de agencias religiosas como el Instituto Lingüístico de Verano (MELIÀ, 1995). En el Chaco, la tarea también implicó un proceso de estandarización gramatical del qom bajo la variedad dialectal hablada en el centro y noroeste provincial:

[...] during most of the month May, the Gospel of Mark was revised and a tentative mimeographed edition of fifty copies was published. These copies are in the hands of many of the church leaders and other interested persons who may be able to help in weeding out translation errors and deficiencies. As well, to check for dialect discrepancies..$^{10}$ (BUCKWALTER, 1965, p. 1).

La tarea misional de escrituración fue un espacio de ejercicio del poder sobre la escritura: los misioneros intervinieron en la definición de las normas de escrituración del qom, las formas de su enseñanza, los usos y los espacios legitimados para ponerlo en práctica, siendo el religioso el dominio por excelencia (PETRUCCI, 1985; 1988; 1993).

\section{ESCRITOS (DE) QOM EN EL DOMINIO RELIGIOSO. DE LA CONSTRUCCIÓN DE UNA COMUNIDAD INDÍGENA LECTORA A LA}

\footnotetext{
${ }^{10}$ En castellano: durante la mayor parte del mes de Mayo, el Evangelio de Marcos fue revisado y una edición mimeografiada tentativa de cincuenta copias fue publicada. Estas copias se encuentran en las manos de muchos de los líderes de la iglesia y otras personas interesadas quienes pueden ayudar en eliminar nuestros errores de traducción y deficiencias. Asimismo, pueden ayudar a controlar las discrepancias dialectales. Traducción realizada por Jesús Lenain del Departamento de Lenguas Extranjeras, Fac.de Humanidades, UNNE.
} 


\section{PRÁCTICA DE ESCRITURA EN QOM}

En la configuración del campo sociorreligioso del evangelismo étnico fue fundamental la difusión de la cultura escrita, constituyéndose el dominio religioso en un espacio privilegiado de apropiación del mundo letrado entre los indígenas. En perspectiva de mediana duración, el proceso estuvo vinculado a la historia general del protestantismo y, particularmente, a la historia de su ramificación entre indígenas del Chaco argentino. En este proceso tuvo un lugar preponderante la lectura directa de las sagradas escrituras, lo cual le otorgó al evangelismo el lugar de "religión del libro" (LYONS, 2012). En el contexto argentino, desde su inserción a principios del siglo XX los misioneros protestantes desarrollaron una política de promoción de la lectura relacionada principalmente con la evangelización y la formación teológica.

La Biblia fue el canon literario principal en este dominio, que pasó a constituirse en la lectura de cada fiel (CHARTIER, 1999). Para promover la lectura en lengua vernácula se propició un conjunto de condiciones materiales: los misioneros protestantes intervinieron en la escrituración de idiomas indígenas de la región; tradujeron fragmentos de la Biblia, elaboraron textos para la enseñanza de la lectura y escritura (cartillas de alfabetización, vocabularios y gramáticas), y escritos varios de carácter religioso (epístolas, himnarios, actas eclesiásticas). De manera conjunta, las prácticas de alfabetización religiosa acompañaron al proceso de estandarización de las lenguas nativas y a la apropiación de la cultura escrita (ARTIEDA, 2012; CERIANI CERNADAS, 2011; ALMIRON, 2014).

En la historia de intervención misional entre indígenas del Chaco argentino, lo distintivo de la década del '50-'70 fue la creación de la IEU y la escrituración del qom, procesos estructurantes que cristalizaron la difusión del evangelio y conformación del campo sociorreligioso étnico. Según describió Wright (1987, p. 8):

La influencia de los textos cristianos traducidos se da a través de cartillas que confeccionan los menonitas [...]. También redactan papeletas que contienen alguna reflexión sobre temas bíblicos a las que suele añadírsele un cronograma de las principales actividades que desarrollará la IEU en sus distintos asentamientos de la región chaqueña. Esto permite lograr una distribución dinámica de información en lengua toba, y contribuye a que la vida institucional de la IEU -"cultos", bautismos, reuniones generales- sean conocidas por un gran número de personas. Por toda la geografía del Chaco circulan 
libros bíblicos, cartillas, almanaques, etc. escritos en toba de la región de Sáenz Peña y Castelli [...].

A partir de estas condiciones simbólicas y materiales, los indígenas hicieron usos heterogéneos de las prácticas de escritura y de lectura. Aunque en determinados espacios se difundieron socialmente en simultáneo, requieren de una doble historización buscando aprehender cómo se fueron constituyendo las capacidades históricas de leer y de escribir dentro del dominio religioso. A continuación nos centramos en materiales escritos en qom por indígenas, orientando el análisis alrededor de la serie de interrogantes canónicos: qué, cuándo, cómo, quién, por qué, para quién se escribe (PETRUCCl, 2002, p. 32).

En el corpus seleccionado hallamos indicios de prácticas y textos diversos producidos por indígenas de las provincias del Chaco y Formosa en este período. Usos religiosos, lingüísticos y educativos, que no se presentaban de manera aislada, sino que estaban interrelacionados e inscriptos en el dominio religioso. Entre otros, los qom escribieron epístolas, reflexiones bíblicas y participaron en la elaboración de cartillas de alfabetización. Materiales escritos monolingües en qom o bilingües qom-castellano. Seguidamente presentamos tres ejemplos que hemos enumerado: las dos primeras consisten en una escritura individual, manuscrita o impresa, la tercera en una autoría colectiva en la que participaron indígenas y misioneros protestantes no indígenas.

\section{a. Naua qom l'aqtaqa (En lengua qom). Epístolas indígenas en el dominio religioso}

Entre 1965-1970 el qom Carlos Mansilla, residente en ese momento en la localidad de San Carlos (Formosa), escribió y envió un conjunto de once cartas destinadas a Llanooxochi o Albert Buckwalter. Son escrituras manuscritas, en cursiva, en idioma castellano o bilingües qom-castellano, generalmente en papel de cuaderno.

El contenido de las cartas se refiere a actividades religiosas de la localidad; escenas de lectura individual y colectiva; del aprendizaje del qom escrito y el castellano; la creación de espacios de enseñanza para "aprender el idioma (qom)"; solicitudes recurrentes de envíos de textos escritos en castellano y en qom. Son 
fuentes que permiten evidenciar el valor significativo que la cultura escrita tenía para Mansilla ${ }^{11}$.

Hermano

Alberto

hace mucho año que no escribo ahora te mando esta carta sabe que yo quiero una revista visual si tiene que me mande [...] y quiero una revista de letra de Toba y Castillano por favor hermano Alberto que me contesta. (MANSILLA, 31 de mayo de 1965).

[...] hermano Llaanoxochi yo poco entindo de mi yoma pero yo lee siempre yo quiero que mande más de mi palabra mia por su cartita ha tecto de la Biblia mejor y mi hijito tambien conozco poco de nuestra palabra nosotros no sabemos todos los Castillanos. (MANSILLA, 23 diciembre de 1965).

[...] quiero que me manda la constestaciónes (naua qom l'aqtaqa) sabe hermano de mi alumno quieres conocer de nuestra dioma. ${ }^{12}$ (MANSILLA, noviembre de 1966. El destacado en negrita es nuestro).

En el fragmento precedente puede leerse cuando aparece por primera vez, en dicho intercambio epistolar, una frase en qom escrita por Mansilla. A partir de 1967 las cartas fueron bilingües, lo que nos sugiere el aprendizaje progresivo que Carlos Mansilla tuvo del qom escriturado. Asimismo, pueden vislumbrarse las prácticas de lectura en qom que le precedieron:

Estimado hermano don Llaanoxochi amm ỹaqaỹa am ỹataxala madé ha badiaten dan I,a,tax ni Dios y ya sabe leer la Biblia pero yo no sabe decir, y leo su carta del mensaje de la palabra de Dios. ${ }^{13}$ (MANSILLA, noviembre de 1967. El destacado en negrita es nuestro).

Bueno hermano Alberto no te olvide cuando hay libro de hecho por la Eyoma de Toba.

Este hermano Alberto ustede sabe todo la yoma de Toba cuando me escriba entonce con la yoma de Toba.

este yo creo avan hacer al hermano de 19 de abril

\footnotetext{
${ }^{11}$ Advertimos que en las transcripciones de los textos escritos por los qom respetamos la ortografía original en los dos idiomas.

12 En castellano: (la lengua qom). Traducción realizada por David García.

${ }^{13}$ En castellano: Llaanoxochi a vos mi hermano mi líder tu que saber la palabra de Dios. Traducción realizada por David García.
} 


\section{Nagui Samaq da iquinaxanaxac 'enauac na ỹaqaỹanicpi na netaña na} Chaco Sáenz Peña. ${ }^{14}$ (MANSILLA, marzo de 1969. El destacado en negrita es nuestro).

Y saludo al hemano don Miguel todos los hermanos los que gosande

Y tu carta yo lee de nuestra dioma y la gente contenta sabe bien porque nuestra diomas. (MANSILLA, noviembre de 1969).

El último material epistolar que presentamos (imagen 5) nos aporta indicios sobre la función otorgada a la escritura en qom, que constituía un medio privilegiado para la comunicación con el menonita Buckwalter y la lectura de versículos o capítulos de la Biblia que eran traducidos al idioma y difundidas en la región. Anticipamos la traducción al castellano del fragmento en qom que se observa en la fuente:

Ya recibí tu carta la que me enviaste. El día 27 de mayo. Y yo estoy muy agradecido por texto que mandaste. Hermano Llanoxochi manda otro texto del libro de nuestro padre Dios. Que está dentro de la biblia pero en el idioma qom yo entiendo muy poco mi propio idioma pero igual voy a seguir estudiando. (Traducción realizada por David García).

${ }^{14}$ En castellano: Ahora mando saludos a todos mis hermanos de Chaco Sáenz Peña. Traducción realizada por David García. 
Imagen 5 - Epístola de Carlos Mansilla, 1970

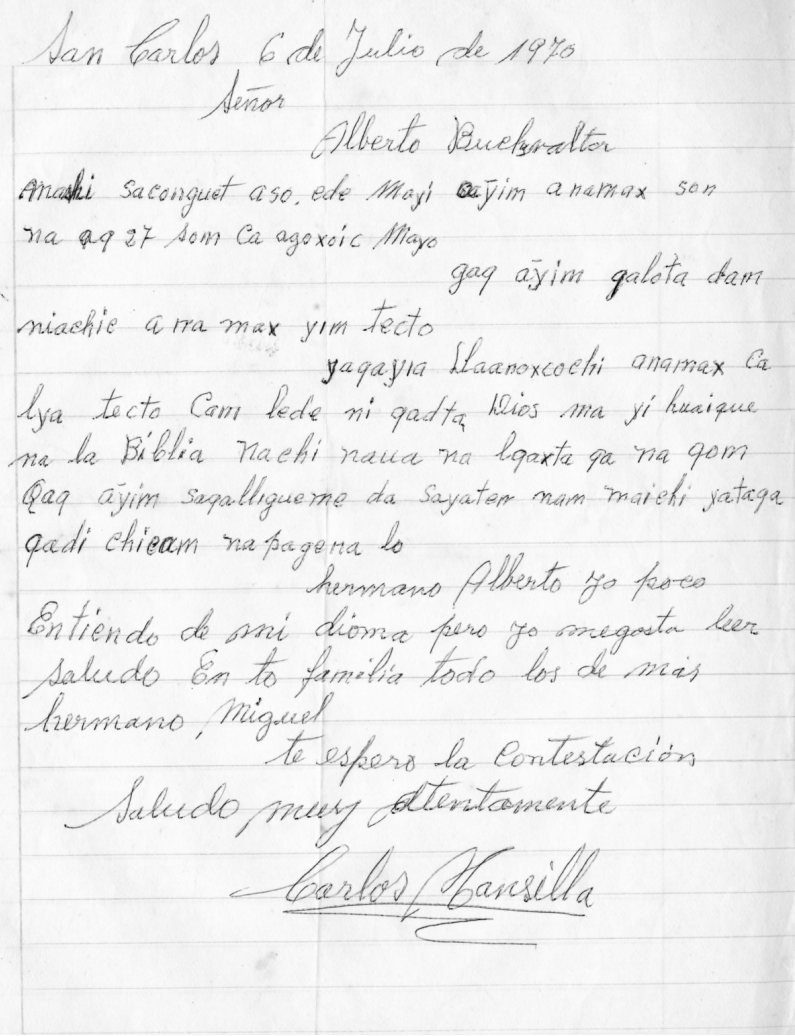

Fuente: Mennonite Church USA Archives.

\section{b. Qad'aqtaxanaxanec. Nuestro Mensajero: de las escrituras marginales y subordinadas de la autoría indígena}

El "boletín oficial" de la IEU fue confeccionado a partir de 1955, y estaba destinado a miembros de las congregaciones diseminadas por el Chaco argentino. La selección de números consultados que abarca el periodo 1958-1977 cuenta con distintas secciones bilingües qom-castellano elaboradas por menonitas y, en algunas, también contó con la participación de indígenas. Fueron editadas en versión impresa evidenciando el interés por su reproducción y difusión. Durante los primeros años Albert Buckwalter fue director de la revista. Tomaremos dos ejemplos para describir sus contenidos y las formas de participación escrituraria de indígenas. 
La edición de noviembre de 1958 (n. 3, Año 3) está escrita en letra imprenta y cuenta con imágenes, algunas de las cuales son fotografías que ilustran escenas de lectura indígena, individuales o colectivas. Incluye reflexiones bíblicas; noticias de actividades de la IUE; un cancionero; un artículo sobre los trabajos de traducción de la Biblia en varios idiomas indígenas, incluyendo versículos bíblicos traducidos (al qom, wichí, pilagá, guaraní, tzeltal, piro); la transcripción de un mensaje oral del qom Antonio Leiva (no se proporcionan referencias del autor de la transcripción).

En una ubicación próxima a los datos editoriales (imagen 6) fue mencionada la colaboración de los indígenas Aurelio López y Manuel Alegre, ambos dirigentes importantes dentro de la jerarquía eclesial de la IEU, sin presentar datos específicos de las formas en que participaron para la elaboración del número. La mención por fuera del recuadro parece hablarnos de una participación escrituraria marginal, y de una relación con la cultura escrita subordinada - al menos en este espacio - a la dirección material y simbólica de los misioneros menonitas:

Imagen 6 - Datos editoriales de la revista Qad'aqtaxanaxanec. Nuestro Mensajero

Avudaron en la preparación de esta revista los siguientes hermanos: Aurelio Iópez, Campo liedina; Kanuel Alegre, Legua 9.

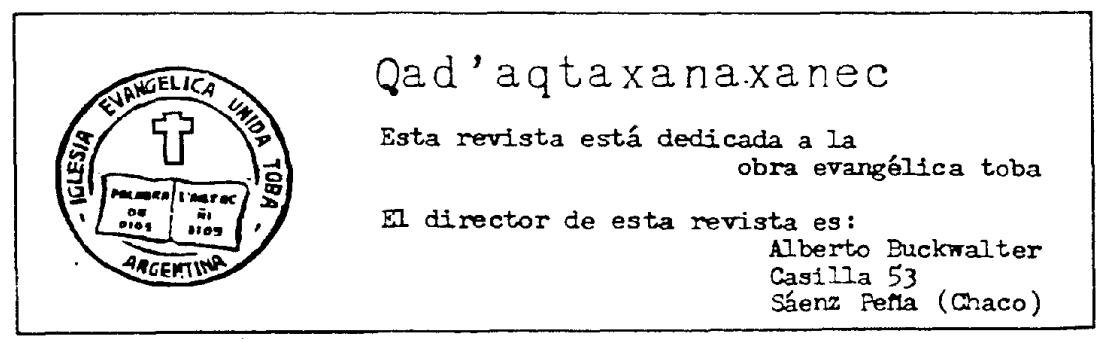

Fuente: www.chacoindigena.net

En la edición de septiembre de 1977 de la revista se incluyeron secciones escritas por indígenas: una de Orlando Sánchez, a quien hicimos referencia anteriormente, que participó con Albert Buckwalter en la traducción de la Biblia al qom; la otra sección fue escrita por Moisés Medina, de Formosa. El texto realizado por Orlando Sánchez cuenta con su autoría indicada al final, está escrito en letra imprenta y exclusivamente en castellano. Se trata de una entrevista al qom Juan Fernández, oriundo del noroeste del Chaco, y su contenido versa sobre la historia de expansión 
del evangelio entre los indígenas de esta provincia. En el relato, Fernández también refirió a sus prácticas de escritura como medio de contacto con el misionero de la iglesia Go Ye: "Escribí a don Juan Lagar, y él me contestó mi carta invitándome a ir para Resistencia" (QAD'AQTAXANAXANEC, 1977, p. 6). En este ejemplo, la escritura cumplía una doble función: lingüística y religiosa. Por una parte, articulaba un discurso oral con la escritura; por otra, contribuía a la socialización de la historia del evangelismo étnico entre los potenciales "lectores religiosos indígenas".

En el escrito de Medina: "Como Dios me ayudó en mi vida", el tipo textual era narrativo, escrito primero en qom y luego en castellano. Describió en primera persona situaciones vivenciales propias, en clave de lectura religiosa:

[...] Qaq ngui na la semana sa ishit da ashic cha'ayi huo'o de'eda estudio. Nachi ñi ilo ỹiguenaaua añi ỹachodo ỹoqchigui nachi nvidaxat. Cha'ayi saxanaxa ishit da sa'ada't cha'ayi can tiempo por el ne'ena estudio Dios l'aqtac.

Yo quiero da aỹim saỹaten y después da ime ne 'ena estuido nchida saáda't ñi ilo, pero mashi huoó ca saỹaten. Nachidata. ${ }^{15}$ (Medina en QAD'AQTAXANAXANEC, 1977, p. 9).

Si bien la sección escrita por Sánchez fue redactada en castellano, la incorporamos porque nos proporciona una lectura global del número y el análisis de ambos textos viabiliza una construcción simbólica religiosa que operaba en el plano colectivo: de "cómo fue recibido el evangelio cuando recién llegó entre los indígenas" (SÁNCHEZ en QAD'AQTAXANAXANEC, 1977, p. 5); pero al mismo tiempo individual, de "como Dios me ayudó en mi vida" (Medina en QAD'AQTAXANAXANEC, 1977, p. 9). Asimismo, a diferencia del boletín de 1958, en el editado en 1977 hay un proceso de construcción, inclusión y visibilización del indígena "autor", es decir, de una escritura de autoría indígena.

\section{c. Lede Qom (Escritos de los Qom). La enseñanza de la lengua qom escriturada}

El último material que presentamos es una cartilla utilizada para la alfabetización en qom en una misión protestante situada en el noroeste del Chaco. Fue elaborada por la alfabetizadora principal, la misionera norteamericana Virginia

${ }^{15}$ En castellano: Ahora no puedo ir a buscar mi bicicleta por el estudio que estamos haciendo esta semana. Pero mandé a mi suegro. El ya trajo mi bicicleta. Cuando termina el estudio voy a armarla. Pero primero quiero aprender la palabra de Dios. Después voy a armar mi bicicleta. Traducción incorporada en Qad'aqtaxanaxanec (1977, p. 10). 
Bunn, en conjunto con el qom letrado José Romero, en consulta con ancianos de la zona para la inclusión de contenidos, y con el asesoramiento lingüístico de Albert Buckwalter. Los datos de autoría y edición no fueron consignados, pero otras fuentes permitieron reconstruir el proceso de producción de la cartilla e identificar la autoría colectiva.

El título de esta cartilla puede ser traducido al castellano como "Escritos de los Qom". (imagen 7) La portada ilustra una escena de lectura entre dos indígenas, en la cual se sugiere que un adulto enseña a leer un texto a un joven, ya que el primero está más cerca del texto y señala unas líneas, y el segundo, más alejado, parece apuntar hacia el mismo lugar. En el título se resumen la modalidad de producción presentada en los apartados anteriores (cartas y boletín en qom), y la escena de lectura donde un indígena enseña a otro (imagen central de portada) proporciona indicios de la relevancia otorgada a la participación indígena. Se trata del marco ideológico antes reseñado, en el que la apropiación de los qom de la cultura escrita constituye un dato central para los misioneros.

Imagen 7 - Lede Qom. Cartilla de alfabetización

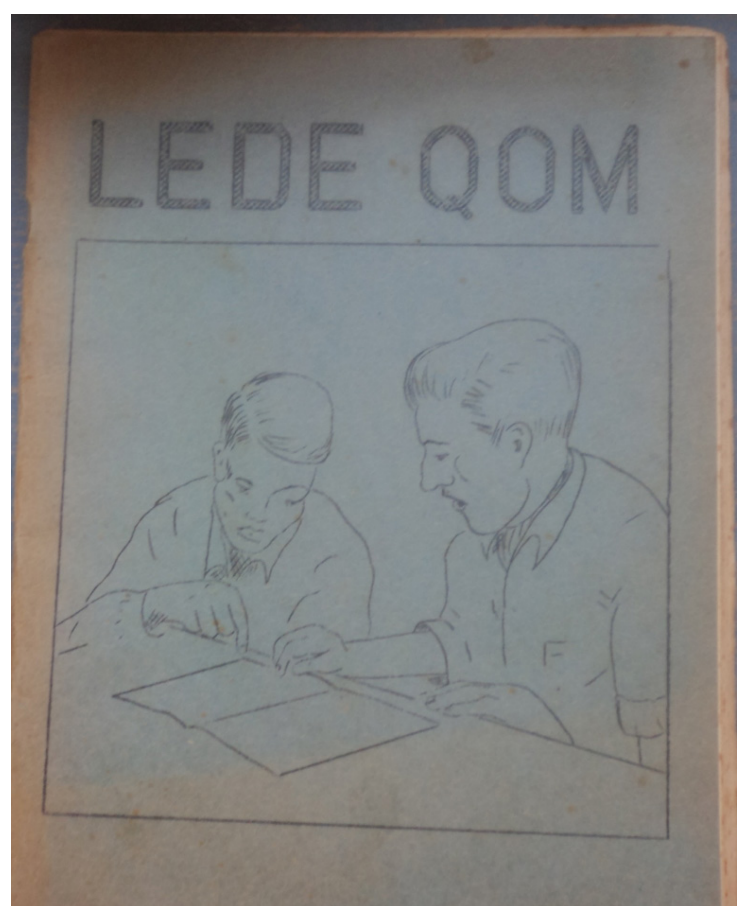

Fuente: Archivo de la Asociación Amigos del Aborigen 
En el proceso de circulación de la cartilla hemos encontrado otra copia con una modificación lingüística parcial al título: "Lede Na Qom" (imagen 8). La misma podría estar relacionada con el proceso de escrituración y el uso de la cartilla entre otras variedades dialectales del qom. Es también la diferencia observada en una cartilla para niños, donde fue incorporado el uso del "Na" y nos sugiere su elaboración posterior.

\section{Imagen 8 - Lede NA Qom, s/f. Cartilla de alfabetización}

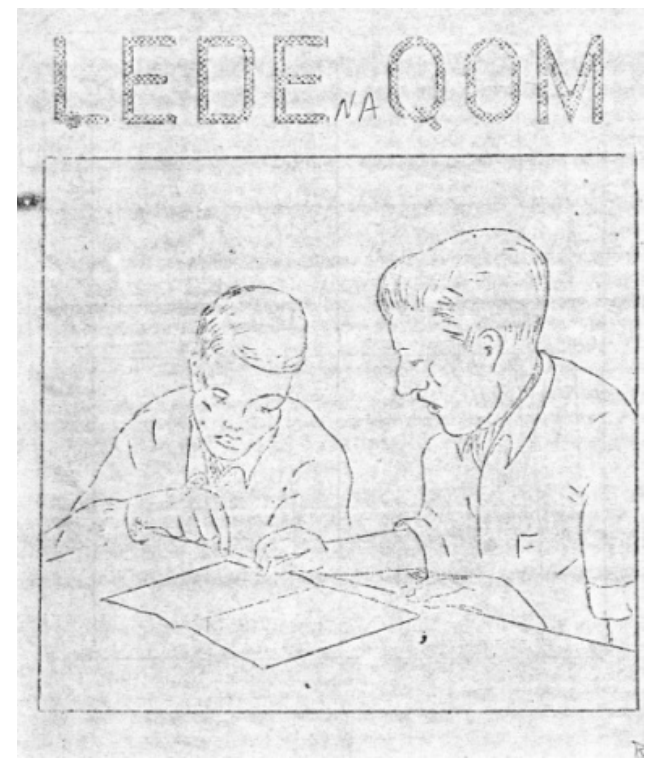

Fuente: Mennonite Church USA Archive.

Además del etnónimo y la corrección, es importante detenerse en el otro término principal que aparece en otras páginas de la cartilla: Nede (libro), que nos ofrece indicios sobre el proceso de estandarización de la lengua y sus expresiones al interior de la alfabetización (imagen 9). En los momentos de traducción y análisis de las cartillas compartidos con el qom David García, una de sus primeras reflexiones fue el uso de la / d/ en vez de la / $r$ / en la palabra Nede: "Pero esa es la que lleva sonido de "ere", se escribe Nede pero es Nere" (entrevista a García, 2017). Varios estudios lingüísticos que cubren variedades de Chaco y Formosa se han ocupado de este fonema /d/ que también se realiza como vibrante simple 
[r] (CENSABELLA, 2002; MESSINEO, 2003; CARPIO, 2012). Esta realización, junto con [d], puede ser pensada como variantes facultativas, es decir, como dos sonidos permutables, que pueden aparecer en los mismos contextos, pero que no producen cambio de significado (GONZÁLEZ, 2015).

En términos de discusiones lingüísticas, el sistema fonológico resulta de una construcción donde, en este caso, parece haberse optado por seleccionar /d/ o / $/$ / a la hora de armar el sistema de escritura del qom. Esto, nos permite evidenciar las relaciones de poder inscriptas en la escritura, donde se impuso un uso sobre el otro y, en términos más generales, un poder sobre la escritura qom definiendo la norma, las formas de enseñanza y los usos legítimos en el grupo social (PETRUCCI, 2002). Es decir, además del contexto multilingüe de la alfabetización, es necesario advertir los procesos de estandarización al interior de la lengua qom y las discrepancias suscitadas entre el lenguaje oral y la escritura. En el caso que nos ocupa, Nede fue la palabra elegida para introducir y reforzar fonológicamente la /d/ en los procesos de enseñanza de la escritura qom:

Imagen 9 - Lede Qom, s/f. Cartilla de alfabetización

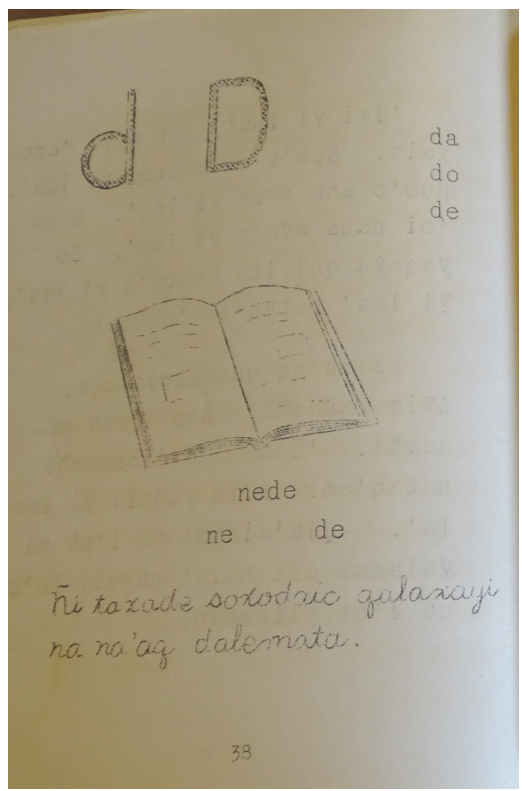

Fuente: Archivo personal José Oyanguren. 
La cartilla está compuesta de 51 páginas y 28 lecturas, introduciendo a la escritura cursiva e imprenta. En cada lectura se recurre al uso de imágenes que representan el tema general abordado (imágenes 10, 11, 12 y 13). La organización del documento permite inferir la secuencia de enseñanza prevista para la alfabetización: en las siete primeras páginas se presentan palabras generadoras, de las cuales se resalta una vocal.

Imágenes 10, 11, 12 y 13 - Lede NA Qom, s/f. Cartilla de alfabetización
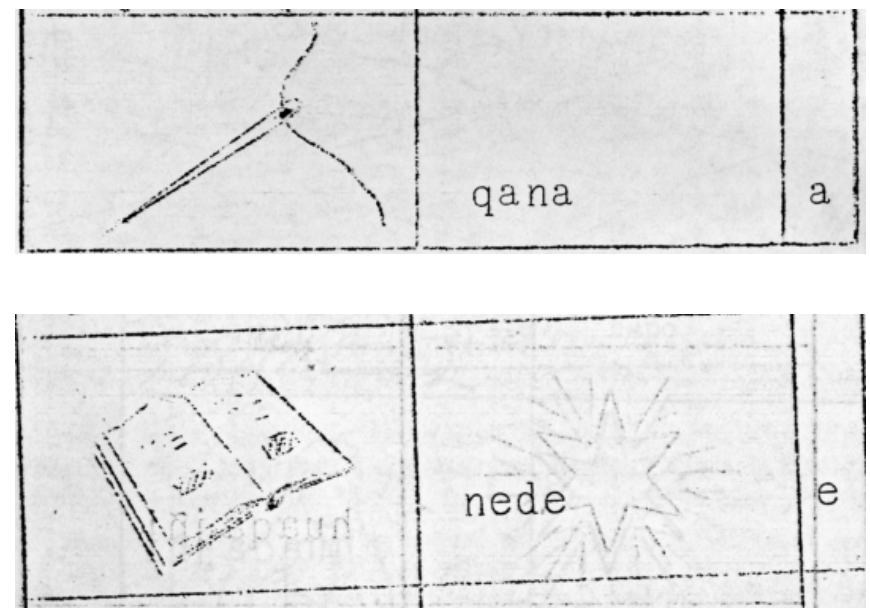

Aguja

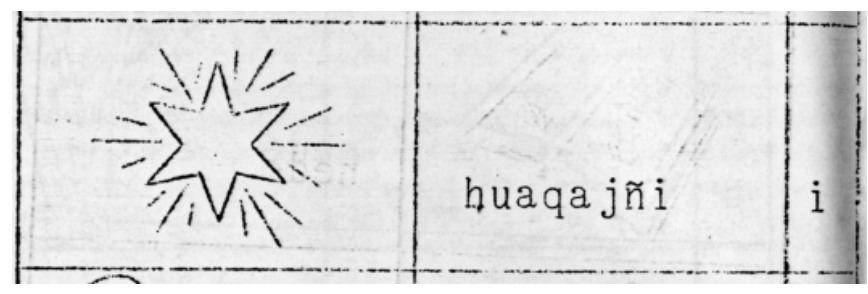

Libro

Estrella

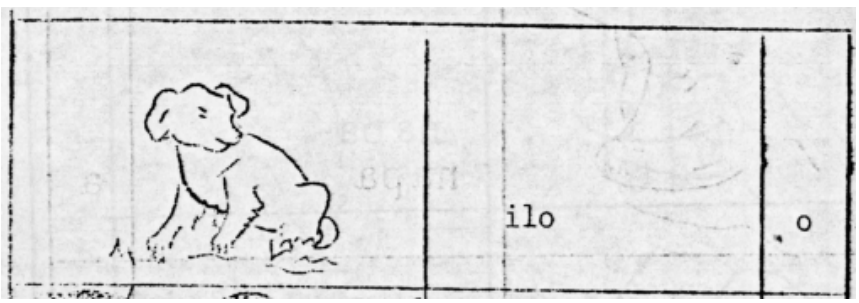

Perro

Fuente: Mennonite Church USA Archive. 
Desde la página 8 a la 51 se van presentando las 21 consonantes del alfabeto qom, que se asocian a una palabra, luego a una oración y finalmente a un texto extendido compuesto por dos a tres párrafos. Tanto la iconografía como la escritura representan acciones ("está llorando", "corramos", "caminando", "vamos a mi casa"), escenas de la vida cotidiana ("me enfermé, estoy enfermo"; "va a llover; está nublado") y del medio circundante del noroeste chaqueño (de lo que en la toponimia qom es denominado "rapiguem" y que es señalado en la cartilla como el monte). Se hace mención a la vegetación (frutos de la recolección como la chaucha del algarrobo), sus usos, los trabajos habituales (por ejemplo, el tejido con chaguar de las mujeres), los juegos infantiles.

La apelación al etnónimo Qom es constante en la cartilla, se la puede hallar en varias lecturas. Aparece como palabra generadora en una de ellas, donde se forman expresiones como "Somos qom, ustedes son qom. Hay muchos qom acá. Somos muchos". La lectura de cierre de la cartilla es sobre la difusión del evangelio y su relación con la cultura escrita; refiere a la llegada en el tren de la Biblia y los himnarios (imagen 14), y su reparto el domingo en la iglesia:

Imagen 14 - Lede Qom. Cartilla de alfabetización. S/f

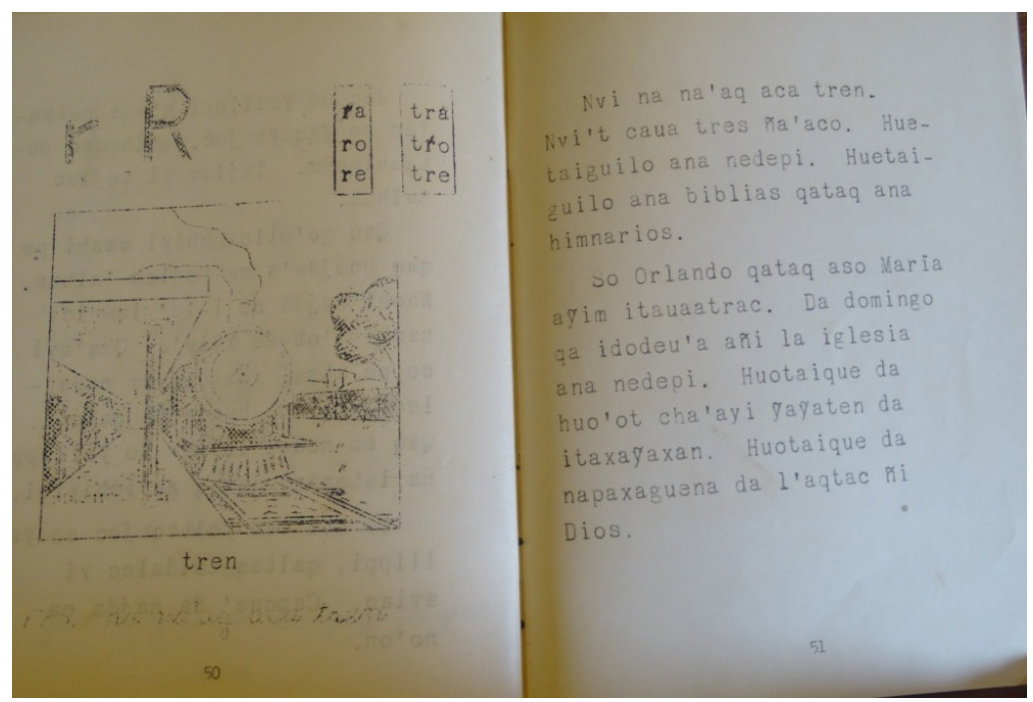

Fuente: Archivo personal José Oyanguren. 


\section{ALGUNAS CONCLUSIONES GENERALES: LECTURAS ENTRE EL PASADO Y EL PRESENTE, EN UNA HISTORIA DE APROPIACIONES MÚLTIPLES}

En los dos subtítulos anteriores describimos la experiencia de inserción misional de protestantes entre indígenas del Chaco argentino y su devenir en la constitución del campo sociorreligioso del evangelismo étnico, deteniéndonos en la creación de la IEU hacia finales de la década del '50. Por sus contribuciones a este último, presentamos sintéticamente la política misional de la Iglesia Emanuel (Formosa) y de la misión Nam Cum (Chaco), aludiendo al proceso de reconfiguración del modelo misional a través de la disolución de la misión y la conformación del grupo "hermanos fraternales" de la IEU.

Asimismo, mostramos el lugar relevante que ocupaba la cultura escrita dentro de los proyectos misionales destinados a indígenas, y reconstruimos concisamente un conjunto de acciones que los misioneros protestantes realizaron: escrituración de los idiomas nativos, traducción de la Biblia, prácticas de alfabetización y elaboración de materiales de lectura. Hicimos referencia de las similitudes de las acciones desarrolladas por el menonita Albert Buckwalter, con lo que dimos cuenta de una continuidad histórica con las prácticas relacionadas con el mundo letrado de otras misiones que la precedieron.

Con ello pudimos dar cuenta de cómo en simultáneo a la apropiación del evangelismo pentecostal y la constitución del campo sociorreligioso étnico, los indígenas se apropiaron de la cultura escrita y del qom escriturado y estandarizado. En ese contexto, reconstruimos prácticas escriturarias de indígenas inscriptas en el dominio religioso. Los resultados nos aportaron indicios de que la práctica de escribir fue realizada sobre todo por varones adultos, no hallándose referencias a los usos de la escritura por parte de mujeres u otros grupos etarios.

Asimismo, pudimos reconstruir que la escritura ocupó un lugar menos destacado con relación a las prácticas de lectura, permitiendo sostener la hipótesis de que durante las primeras décadas (1950-1970), la construcción de la aboriginalidad dentro del dominio religioso estaba más orientada a un indígena lector que escribiente. La construcción como indígena lector y autor tiene una paulatina emergencia hacia finales de los '70. En esta década los misioneros protestantes comenzaron a realizar "Cursillos para escritores" indígenas, como lo evidencia la 
edición del Qad’aqtaxanaxanec de abril de 1979 (imagen 15), donde encontramos referencias a los mismos:

Imagen 15 - Artículo sobre talleres para escritores indígenas. Revista "Qad'aqtaxanaxanec. El Mensajero"

ESCRITORES PARA CRISTO

Con la ayuda de Dios pensamos teriex otro Cursilio para Escritores en el Lote 68, Formosa. La fecha sers del 26 de agosto al 2 de setiembre de este afro. 1979.

si usted quiere paxticipar, hable conmigo, - escriba, dirigiendo su carta a la Casilla 196, Foxmosa. Pensamos invitax a $\mathrm{min}$ o menos 20 personas para el Cursilio.

oren por los jovenes que están aprendiendo a escribir para Cristol
Willis Gabriel Horst y Berta (Qanaxafoxoyi qataq Paloqte) obreros fraterrales Casilla 196, 3600 Formosa

Fuente: Extraído de www.chacoindigena.net

Finalmente, entre los materiales elaborados por el menonita Buckwalter se encontraba el Vocabulario Toba (1980), un texto lingüístico fundamental para la lectura en idioma indígena que a finales de la década de 1980 se utilizaba para la alfabetización inicial en el marco de la Educación Bilingüe Intercultural. En el prefacio del texto, el misionero aludía a la contribución de indígenas para la producción del libro, entre los que destacó a Francisco Rodríguez como ayudante principal durante la primera década.

En la introducción de este artículo referimos al evento de la Feria del Libro efectuada hace pocos meses donde el qom Orlando Sánchez, quien también había participado del proceso de escrituración del qom, la traducción de la Biblia y de la producción del Vocabulario Toba (1980), y en esa ocasión presentó a su vez el Vocabulario Qom explícitamente reivindicado como una herramienta para la "descolonización de la historia qom y de la educación bilingüe e intercultural". 
El recorrido histórico realizado a través de la escritura de distintos textos por parte de algunos referentes indígenas qom (cartas a un misionero, boletín religioso y cartillas de alfabetización), nos permite contextualizar esta expresión de Orlando Sánchez, atendiendo a cómo la participación de los indígenas fue reconocida progresivamente por los misioneros en el marco de la emergencia de una iglesia evangélica de cuño propio, donde los hermanos ocuparon un lugar subordinado pero fundamental: la apropiación de la lengua qom y las prácticas escriturarias en qom reivindicadas por los indígenas del Chaco argentino se inscriben en dichos procesos.

\section{BIBLIOGRAFÍA}

ALMIRON, Victoria. Leer y escribir en Qom. Alfabetización en el marco de un proyecto misional protestante. Juan J. Castelli, Chaco (1964-1973c). In: JORNADAS JÓVENES INVESTIGADORES, 22., Playa Ancha, Valparaiso, Chile. Anales [...]. Playa Ancha: Asociación de Universidades Grupo Montevideo;Universidad de Playa Ancha, 2014.

ARTIEDA, Teresa. Historias indígenas de acceso a la lectura y la escritura en tres ámbitos, religión, familia, escuela (1914-1960 circa). In: CUCUZZA, H.; SPREGELBURD, R (Cord.): Historia de la lectura en la Argentina: del catecismo colonial a las netbooks estatales. Buenos Aires: Editoras del Calderón, 2012. p. 435-70.

BUCKWALTER, A. El Chaco Argentino. Illinois, EEUU: [s.n.]. Mennonite Church USA Archive, 20 de marzo de 1965. (Collection: "Albert S. and Lois Buckwalter Papers, 1949-2004).

BUCKWALTER, A. Missionaries, Tobas, and Athropology. Illinois, EEUU: [s.n.]. Mennonite Church USA Archive, 4 de junio de 1957. (Collection: "Albert S. and Lois Buckwalter Papers, 1949-2004).

BUCKWALTER, A. Are we adequately meeting the need of the Indian through the spanish and interpreters? Or should the mission officially take steps to put the Toba in writing? Illinois, EEUU, Mennonite Church USA Archive, 1951. (Collection Albert S. and Lois Buckwalter Papers, 1949-2004).

BUCKWALTER, Albert; LITWILLER, Lois. Misión a las comunidades autóctonas. In: HORST, W., MULLER ECKHARDT, U.; FRANK, P. (Comp.). Misión sin conquista- Acompañamiento de comunidades indígenas autóctonas como práctica misionera alternativa. Buenos Aires: Kairós Ediciones, 2011.

CARPIO, María Belén. Fonología y morfosintaxis de la lengua hablada por grupos tobas en el oeste de Formosa (Argentina). München: LINCOM Europa Academic Publishers, 2012. 
CASTILLO GÓMEZ, Antonio. Armando Petrucci: un paseo por los bosques de la escritura. LITTERAE - Cuadernos sobre Cultura Escrita, n. 2, p. 9-37, 2002.

CENSABELLA, Marisa. Descripción funcional de un corpus en lengua toba (familia Guaycurú, Argentina): sistema fonológico, clases sintácticas y derivación - aspectos de sincronía dinámica. 2002. Tesis (Doctorado en Letras Modernas) - Universidad Nacional de Córdoba, Córdoba, AR, 2002.

CERIANI CERNADAS, César. Evangelismos étnicos: un ensayo comparativo desde la experiencia toba y gitana. In: ESQUIVEL, J.; GIMÉNEZ BÉLIVEAU, V. (Coord.). Religiones en cuestión: campos, fronteras y perspectivas. Buenos Aires: Fundación CICCUS, 2018. p. 349-36.

CERIANI CERNADAS, César. Entre la confianza y la sospecha. Representaciones indígenas sobre las experiencias chaqueñas de misionalización protestante. In: El Gran Chaco: ontología, poder, afectividad. Buenos Aires: Ethnographica. p. 297-320, 2013b.

CERIANI CERNADAS, César. La religión como categoría social: encrucijadas semánticas y pragmáticas. Revista de Sociedades en Transición, v. VII, n. 1, p. 10-29, $2013 \mathrm{a}$.

CERIANI CERNADAS, César. Liderazgo, conflicto y mediación cultural en las iglesias pentecostales indígenas del Chaco Salteño. In: Jornadas de Alternativas Religiosas en América Latina, 16., Punta del Este, Uruguay, 2011. Anales [...]. Punta del Este: Asociación de Cientistas Sociales de la Religión del Mercosur, 2011.

CERIANI CERNADAS, César. Las enseñanzas de Don Juan Chur entre los Tobas de Formosa (Argentina, 1937-1950). Papeles de trabajo -. Revista electrónica del Instituto de Altos Estudios Sociales de la Universidad Nacional de General San Martín, Año 2, n. 5, p. 1-20, 2009. [Dossier "Artes de lo sagrado en las XIV Jornadas sobre Alternativas Religiosas de América Latina"].

CERIANI CERNADAS, César. El tiempo primordial. Memorias tobas del pastor Chur. Revista de Ciencias Sociales (Cl), n. 18, p. 71-86, 2007.

CERIANI CERNADAS, Cesar; CITRO, Silvia. El movimiento del evangelio entre los tobas del Chaco argentino. Una revisión histórica y etnográfica. De indio a hermano. Pentecostalismo indígena en América Latina, Chile. Iquique: Ediciones el jote errante; Ediciones Capvs, 2005. p. 111-70.

CHARTIER, Roger. Os desafíos da escrita. São Paulo: Ed. Unesp, 2002. 
CHARTIER, Roger. Cultura escrita: literatura e historia - conversaciones con Roger Chartier. México: Fondo de Cultura Económica, 1999.

GARCIA, D. [indígena qom]. Entrevistado por Victoria S. Almiron, en marzo-junio de 2017. Resistencia, Chaco. [cintas de audio].

GONZÁLEZ, Raúl. Estudio fonológico y morfosintáctico de la lengua toba hablada en el este de la provincia de Formosa (Argentina). LINCOM Studies in Native American Linguistics, München, n. 75, 2015.

GORDILLO, Gaston. La lectura de evangelización en la Nueva España. In: CASTAÑEDA GARCÍA, C.; GALVÁN-LAFARGA, L.; MARTínEZ-MOCTEZUMA, L. (Coord.). Historia de la lectura en México. México: El Colegio de México; Centro de Estudios Históricos. 3. reimp., 2005. p. 9-45.

INDERECIO, B. [indígena qom]. Entrevistado por Victoria S. Almiron, en 22 de diciembre de 2015. Barranqueras, Chaco. [cinta de audio].

LEDE, N. A. Qom. Cartilla de alfabetización. Mennonite Church USA Archive, Illinois, EEUU. Collection: Albert S. and Lois Buckwalter Papers, 1949-2004.

LEDE, N. A. Qom. Cartilla de alfabetización. Archivo de la Asociación Amigos del Aborigen. Chaco, Argentina, [s.d.].

LEDE, N. A. Qom. Cartilla de alfabetización. Archivo personal de José Oyanguren, [s.d.].

LITWILLER, L. Entrevistado por Victoria S. Almiron, en 11 de junio de 2016. [on line].

LYONS, Martin. Historia de la lectura y de la escritura en el mundo occidental. Buenos Aires: Editoras Del Calderón, 2012.

MANSILLA, C. Carta de 6 de julio de 1970. Mennonite Church USA Archive, Illinois, EEUU. Collection: Albert S. and Lois Buckwalter Papers, 1949-2004.

MANSILLA, C. Carta de 17 de noviembre de 1969. Mennonite Church USA Archive, Illinois, EEUU. Collection: Albert S. and Lois Buckwalter Papers, 1949-2004.

MANSILLA, C. Carta de 30 de marzo de 1969. Mennonite Church USA Archive, Illinois, EEUU. Collection: Albert S. and Lois Buckwalter Papers, 1949-2004.

MANSILLA, C. Carta de 10 de noviembre de 1967. Mennonite Church USA Archive, Illinois, EEUU. Collection: Albert S. and Lois Buckwalter Papers, 1949-2004. 
MANSILLA, C. Carta de 2 de noviembre de 1966. Mennonite Church USA Archive, Illinois, EEUU. Collection: Albert S. and Lois Buckwalter Papers, 1949-2004.

MANSILLA, C. Carta de 23 de diciembre de 1965. Mennonite Church USA Archive, Illinois, EEUU. Collection: Albert S. and Lois Buckwalter Papers, 1949-2004.

MANSILLA, C. Carta de 31 de mayo de 1965. Mennonite Church USA Archive, Illinois, EEUU. Collection: Albert S. and Lois Buckwalter Papers, 1949-2004.

MASES, Enrique. Estado y cuestión indígena. El destino final de los indios sometidos en el sur del territorio (1878-1930). Buenos Aires: Prometeo libros, 2010.

MAST, M. Una aproximación a la educación teológica entre los Tobas de Argentina. Tesis Licenciatura en Misiología para la Escuela de Misión Mundial del Seminario Teológico Fuller en Pasadena California, EEUU, 1972. [Archivo personal José Oyanguren].

MELIÀ, Bartomeu. Elogio de la lengua guaraní. Contextos para una educación bilingüe en el Paraguay. Asunción: Centro de Estudios Paraguayos “Antonio Guasch”, 1995.

MESSINEO, Cristina. Lengua toba (guaycurú). Aspectos gramaticales y discursivos. München: LINCOM Europa Academic Publishers, 2003.

OLIVEIRA GALVÃO, Ana María. História da cultura escrita: tendências e possibilidades de pesquisa. In: MARINHO, M.; CARVALHO, G. (Org.). Cultura escrita e letramento. Belo Horizonte: Ed. UFMG, 2010. p. 218-48.

PETRUCCI, Armando. Introduzione alle pratiche di scrittura. En: Annali della Scuola Normale Superiore di Pisa, XXIII, 2, 1993. p. 549-62.

PETRUCCl, Armando. Pouvoir de l'écriture, pouvoir sur l'écriture dans la Renaissance italienne. Economies, sociétés, civilisations, año 43, n. 4, p. 823-47, 1988.

PETRUCCl, Armando. Potere, spazi urbani, scritture esposte: proposte ed esempi. In: Culture et idéologie dans la genèse de l'État moderne. Actes de la table ronde de Rome. Rome: École Française de Rome, 1985. p. 85-97.

QAD'AQTAXANAXANEC. Nuestro Mensajero, abr. 1979. Disponible en: http:// chacoindigena.net/Iglesias_indigenas_files/1979\%20-Abril.pdf

QAD'AQTAXANAXANEC. Nuestro Mensajero, sep. 1977. Disponible en: http:// chacoindigena.net/Iglesias_indigenas_files/1977\%20-Septiembre.pdf. 
QAD'AQTAXANAXANEC. Nuestro Mensajero, año 3, n. 3. 1958. Disponible en: http:// chacoindigena.net/Iglesias_indigenas_files/1958\%20-Noviembre.pdf

REYNBURN, William ([1954] 2003). The Toba Indians of the Argentine Chaco: An interpretive report. Edición al castellano. Indiana, USA: Mennonite Board of Missions \& Charities. Disponível em: http://chacoindigena.net/Textos_etnologicos_files/W.ReyburnLos\%20Tobas\%20del\%20Chaco\%20Argentino\%20\%28informe\%20interpretativo\%20 del\%201.954\%29.pdf.

ROCKWELL, Elsie. Relaciones con la cultura escrita en una comunidad nahua a principios del Siglo XX: temas recurrentes. Revista Lingua Escrita, n. 4, p. 1-17, 2008.

ROCKWELL, Elsie. Apropiaciones indígenas de la escritura en tres dominios: religión, gobierno y escuela. Cultura Escrita \& Sociedad, n. 3, p. 161-218, 2006.

ROCKWELL, Elsie. La otra diversidad: historias múltiples de apropiación de la escritura. DiversCité Langues, v. V, 2000. Disponible en: http://www.teluq.uquebec.ca/diverscite.

ROMERO, C. [indígena qom]. Entrevistado por Victoria S. Almiron, en marzo de 2017. Barranqueras, Chaco. [Cinta de audio].

SÁNCHEZ, Orlando. Cronología de la formación y del crecimiento de la Iglesia Evangélica Unida en el norte de la Argentina. Chaco Indígena, 2005. Disponible en: http:// chacoindigena.net/Iglesias_indigenas_files/Orlando\%20Sanchez-CRONOLOGIA\%20 DE\%20LA\%2OFORMACION\%20Y\%20DEL\%20CRECIMIENTO\%20DE\%20LA\%2OIGLESIA\%20 evangelica\%20unida.pdf

SANCHEZ, Orlando. Da na' aqtaguec nam Qompi Toba. Mayi Ima' na Ita'adaic Chaco nam ya'axat som lquedoxonecpi na mayipi. Resistencia: Subsecretaría de Educación y Librería de la Paz, 2009.

SOTAGAG, G. [indígena qom]. Entrevistado por Victoria S. Almiron, en marzo de 2017. Juan J. Castelli, Chaco. [Cinta de audio].

TOLA, Florencia. Una revisión de los etnónimos de los Toba (Qom) del Chaco argentino en función de la categoría de persona y de la vida social. Publicar, v. 1, p. 171-85, 2010.

TORRES Fernández, Patricia. Políticas misionales anglicanas en el Chaco Centro-Occidental a principios del siglo XX: entre comunidades e identidades diversas. Población y sociedad. n. $14 / 15$, p. $139-76,2007 / 2008$. 
TRINCHERO, Hugo. Los dominios del demonio. Civilizacion y barbarie en las fronteras de la Nacion. El Chaco central. Buenos Aires: Eudeba, 2000.

WRIGHT, Pablo. Iglesia evangélica unida: tradición y aculturación en una organización socio-religiosa Toba contemporánea. En: REUNIÓN LATINOAMERICANA SOBRE RELIGIÓN POPULAR, IDENTIDAD Y ETNOCIENCIA, 1., México, 1987. Anales [...]. México: Escuela Nacional de Antropología e Historia, 1987.

GÓMEZ, Mariana ¿Morirán mis hijos o las frutas del monte se secarán si no canto y uso mi amuleto cada noche? Mujeres tobas (qom) y Misioneros Anglicanos en el Chaco Centro occidental (Argentina). Cadernos Pagu, n. 36, pp 187-222. 2011.

Tamagno, Liliana. Religión y procesos de movilidad étnica La Iglesia Evangélica Unida, expresión sociocultural del pueblo toba en Argentina. IZTAPALAPA Revista de ciencias sociales y humanidades. Año, 28, n. 62-63, pp. 69-99. 2007.

\section{Sobre as autoras:}

Soledad Almiron: Doctora, Especialista y Diplomada Superior em Ciencias Sociales. Becaria Posdoctoral del CONICET con sede en el Instituto de Investigaciones Geohistóricas (IIGHI), docente universitaria (UNNE). E-mail: sol_almiron@live.com.ar. Orcid: https://orcid.org/0000-0002-3790-3698

Ana Padawer: Doctora de la Universidad de Buenos Aires con orientación en Antropología. Investigadora Independiente del CONICET, docente universitária (UBA). E-mail: apadawer66@gmail.com, Orcid: https://orcid.org/0000-0003-4024-4723

Recibido el 20 de mayo de 2020

Aprobado para su publicación el 21 de noviembre de 2020 